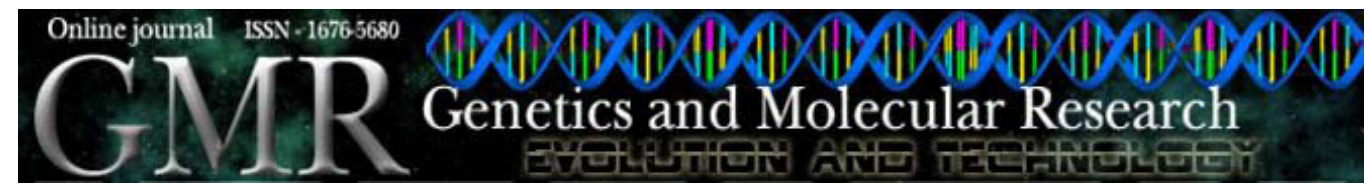

\title{
Development of a species-diagnostic marker and its application for population genetics studies of the stingless bee Trigona collina in Thailand
}

\author{
M. Theeraapisakkun ${ }^{1}$, S. Klinbunga ${ }^{2,3}$ and S. Sittipraneed ${ }^{1}$ \\ ${ }^{1}$ Department of Biochemistry, Faculty of Science, Chulalongkorn University, \\ Bangkok, Thailand \\ ${ }^{2}$ National Center for Genetic Engineering and Biotechnology, \\ National Science and Development Agency, Pathumthani, Thailand \\ ${ }^{3}$ Center of Excellence for Marine Biotechnology, Faculty of Science, \\ Chulalongkorn University, Bangkok, Thailand \\ Corresponding author: S. Sittipraneed \\ E-mail: Siriporn.S@chula.ac.th
}

Genet. Mol. Res. 9 (2): 919-930 (2010)

Received January 18, 2010

Accepted February 23, 2010

Published May 18, 2010

DOI 10.4238/vol9-2gmr775

\begin{abstract}
A molecular maker for authenticating species origin of the stingless bee (Trigona collina) was developed. Initially, amplified fragment length polymorphism analysis was made of 11 stingless bee species using 64 primer combinations. A 316-bp band found only in T. collina was cloned and sequenced. A primer pair (CUTc1-F/R) was designed and tested for species-specificity in 15 stingless bee species (239 nests). The expected 259-bp fragment was consistently amplified in all T. collina individuals (134/134 nests, 100\%). Cross-species amplification was observed in T. pagdeni (43/51 nests; 84.3\%), but not in other species. SSCP analysis of CUTc1 unambiguously differentiated T. collina from T. pagdeni. CUTc1 generated three genotypes in Thai T. collina (134 nests). An AA (259/259 bp) genotype was found in all stingless bees from the north (21 nests) and northeast (32 nests), and 23/28 nests from the Central region, whereas a BB (253/253 bp) genotype was observed in most samples from peninsular Thailand (42/53 nests). Heterozygotes exhibiting the AB (253/259 bp) genotype
\end{abstract}


were observed in 5 of 28 nests from Prachuap Khiri Khan located slightly above the Kra ecotone and 11 of 53 nests originated further south of the Kra ecotone. Genotype distribution patterns of CUTc1 clearly indicated intraspecific population differentiation of Thai T. collina.

Key words: Stingless bees; Trigona collina; AFLP; SSCP; Species-specific marker; Population differentiation

\section{INTRODUCTION}

Stingless bees are eusocial insects (Meliponini, Family Apidae, Order Hymenoptera) widely distributed over tropical and subtropical regions worldwide (Michener and Sakagami, 1990; Michener, 1974, 2007). They play an important ecological role as effective pollinators of many plant species, both wild and cultivated (Heard, 1999; Amano et al., 2000; Slaa et al., 2000) and seem to be good candidates for future applications as commercial pollinators (Slaa et al., 2000, 2006).

Thirty-two Trigona species have been described in Thailand (Schwarz, 1939; Sakagami et al., 1983; Michener and Boongird, 2004; Klakasikorn et al., 2005). Of these, T. collina and T. pagdeni are predominant and commonly distributed throughout vast geographic locations in Thailand, the Malaysian peninsula and the Indochina region (Sakagami, 1978; Sakagami and Khoo, 1987).

Taxonomic identification of stingless bees remains unclear and requires experienced scientists (Michener, 1961; Dollin et al., 1997). Sakagami (1978) reported taxonomic difficulties in several Indo-Malayan stingless bees. Nest architecture characters are usually relevant, but it has been reported that they are not sufficient criteria for authenticating species origins of Australian stingless bees (T. hockingsi and T. davenporti) (Franck et al., 2004).

Many Trigona are sympatric species (e.g., between T. pagdeni and T. fuscobalteata; Sakagami, 1978) and cannot be preliminary distinguished based on geographic distribution. In addition, species recognition of stingless bees is complicated because of cryptic species (e.g., between T. carbonaria and T. hockingsi and between T. iridipennis and T. laeviceps; Starr and Sakagami, 1987). Therefore, species-diagnostic markers for reliable differentiation of abundantly distributed species such as T. collina are a prerequisite for eliminating confusion of morphologically similar species in genetic diversity and population structure analyses of this species.

Here, we looked for species-diagnostic genetic markers to distinguish T. collina from other stingless bees in Thailand.

\section{MATERIAL AND METHODS}

\section{Sampling}

Adult workers of 15 Trigona species were collected from geographically different locations in Thailand (Figure 1). Specimens were placed in $95 \%$ ethanol and kept at $4{ }^{\circ} \mathrm{C}$, until required. Taxonomic identification of these stingless bees was made based on nest architecture and bee morphology, according to Sakagami (1978) and Sakagami et al. (1983). Species origins of specimens were kindly confirmed based on external morphology by Dr. Charles D. Michener (University of Kansas). Voucher specimens were deposited in the University of Kansas Snow Entomological Collection. 


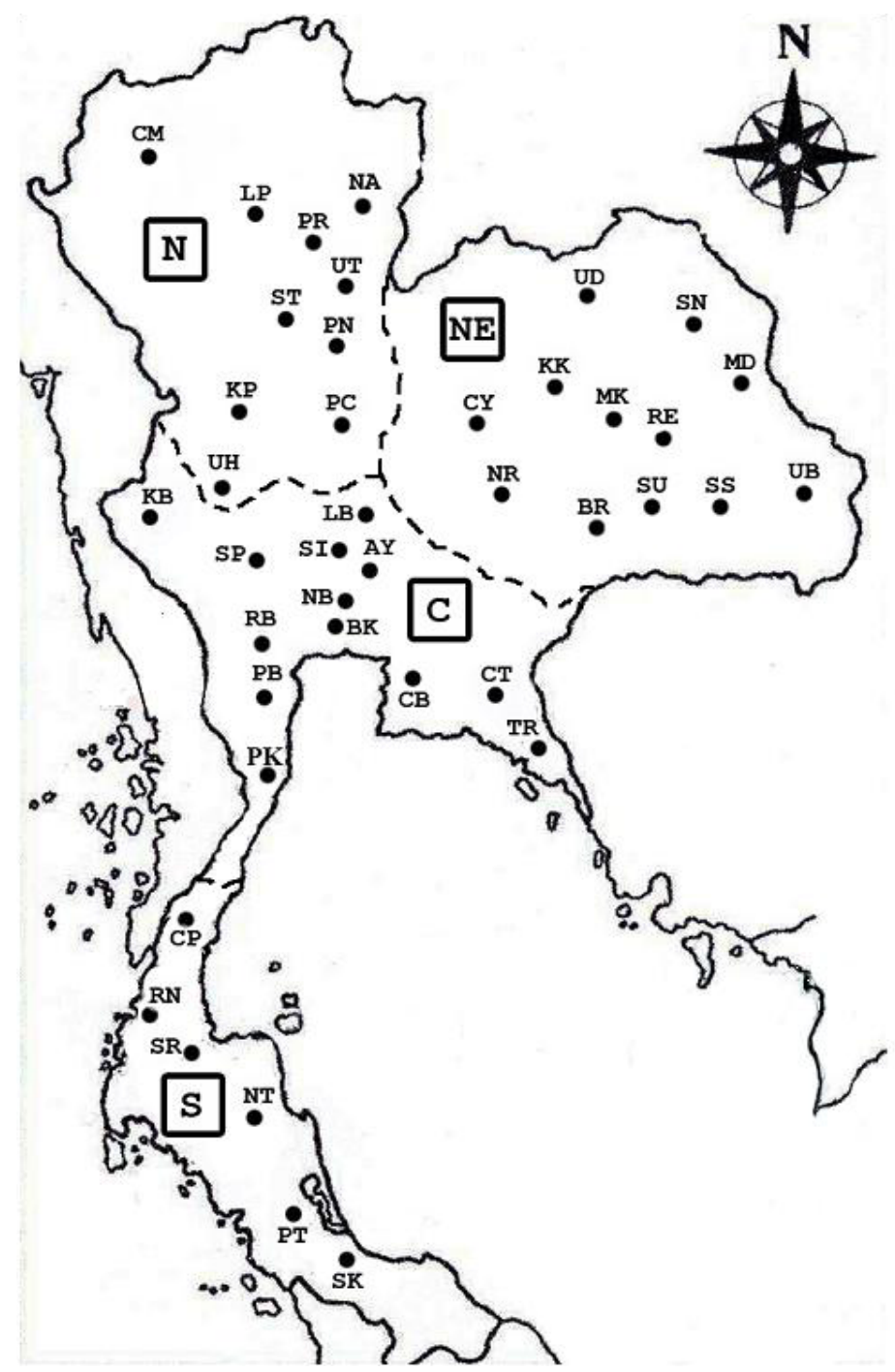

Figure 1. Collection sites of Trigona collina samples used in this study. Abbreviations corresponding to locations are shown in Table $1 . \mathrm{N}=$ North; $\mathrm{NE}=$ Northeast; $\mathrm{C}=$ Central region; $\mathrm{S}=$ Peninsular Thailand.

\section{Amplified fragment length polymorphism analysis}

Total DNA was extracted from each stingless bee using a phenol-chloroform-SDS method (Smith and Hagen, 1996). Amplified fragment length polymorphism analysis (AFLP) of 11 stingless bee species (excluding T. laeviceps, T. melanoleuca, T. terminata, and Lisotrigona furva; Table 1) was carried out, as described by Vos et al. (1995). Briefly, pooled genomic DNA (250 ng) of stingless bees from the same colony was digested with PstI and MseI prior to ligation with restriction site-specific adaptors. Preamplification was carried out utilizing adap- 
tor-specific primers with a single selective base on each primer (5'-GACTGCGTACATGCAG A-3' and 5'-GATGAGTCCTGAGTAAC-3'). The preamplification product was diluted 25-fold and selectively amplified with 64 primer combinations having three selective bases at the 3 ' terminus of each primer. Polymerase chain reaction (PCR) was performed consisting of 2 cycles of denaturation at $94^{\circ} \mathrm{C}$ for $45 \mathrm{~s}$, annealing at $65^{\circ} \mathrm{C}$ for $60 \mathrm{~s}$, and extension at $72^{\circ} \mathrm{C}$ for $90 \mathrm{~s}$, followed by 10 cycles of a touchdown phase with lowering of the annealing temperature $0.7^{\circ} \mathrm{C}$ at every cycle and an additional 25 cycles of $94^{\circ} \mathrm{C}$ for $45 \mathrm{~s}, 56^{\circ} \mathrm{C}$ for $60 \mathrm{~s}$, and $72^{\circ} \mathrm{C}$ for $90 \mathrm{~s}$. The final extension was carried out at $72^{\circ} \mathrm{C}$ for $5 \mathrm{~min}$. AFLP were size-fractionated through $6 \%$ denaturing polyacrylamide gels (19:1 crosslink) and visualized by silver staining.

\begin{tabular}{|c|c|c|c|c|c|c|c|c|c|c|c|c|c|c|c|}
\hline Location / Species & Tapi & Tcan & Tcol & Tdoi & Tfim & Tfus & Titm & Tlae & Tmela & Tmel & Tmin & Tpag & Tter & Ttho & Lfur \\
\hline \multicolumn{16}{|l|}{ Central region } \\
\hline Ayutthaya (AY) & - & - & - & - & - & - & - & - & - & - & - & 1 & - & - & - \\
\hline Bangkok (BK) & - & - & - & - & - & - & - & - & - & - & - & 5 & - & - & - \\
\hline Chonburi (CB) & - & - & - & - & - & - & - & - & - & - & - & 2 & - & - & - \\
\hline Chanthaburi (CT) & - & - & 1 & - & - & - & - & - & - & - & - & 3 & - & - & - \\
\hline Kanchanaburi (KB) & - & - & 14 & - & - & 3 & - & - & - & - & - & 4 & - & - & - \\
\hline Lopburi (LB) & - & - & - & - & - & - & - & - & - & - & - & 2 & - & - & - \\
\hline Nonthaburi (NB) & - & - & - & - & - & - & - & - & - & - & - & 2 & - & - & - \\
\hline Phetchaburi (PB) & - & - & - & - & - & - & - & - & - & - & - & 3 & - & - & - \\
\hline Prachuap Khiri Khan (PK) & - & - & 12 & - & - & - & - & - & - & - & - & 5 & - & - & - \\
\hline Ratchaburi (RB) & 4 & - & 1 & - & - & - & - & - & - & - & - & - & 1 & - & 1 \\
\hline Singburi (SI) & - & - & - & - & - & - & - & - & - & - & - & 2 & - & - & - \\
\hline Suphanburi (SP) & - & - & - & - & - & - & - & - & - & - & - & 1 & - & - & - \\
\hline Trat (TR) & - & - & - & - & - & - & - & - & - & - & - & 2 & - & - & - \\
\hline \multicolumn{16}{|l|}{ North } \\
\hline Chiang Mai (CM) & 2 & - & - & 1 & 1 & 1 & - & - & 1 & - & - & 4 & - & - & - \\
\hline Kamphaeng Phet (KP) & 2 & - & 3 & - & - & - & - & - & - & - & - & - & - & - & - \\
\hline Lampang (LP) & - & - & - & - & - & - & - & - & - & - & - & - & 2 & - & - \\
\hline Nan (NA) & - & - & 2 & - & - & - & - & - & - & - & 1 & 1 & - & - & - \\
\hline Phichit (PC) & - & - & 3 & - & - & - & - & 3 & - & - & - & - & - & - & - \\
\hline Phitsanulok (PN) & - & - & - & - & - & - & - & 2 & - & - & - & - & - & - & - \\
\hline Phrae (PR) & - & - & 3 & - & - & 1 & - & 1 & - & - & - & - & - & - & - \\
\hline Sukho Thai (ST) & - & - & - & - & - & - & - & - & - & - & - & 3 & - & - & - \\
\hline Uthai Thani (UH) & - & - & 8 & - & - & - & - & - & - & - & - & - & - & - & - \\
\hline Uttaradit (UT) & - & - & 2 & - & - & 1 & - & - & - & - & 3 & - & 1 & - & - \\
\hline \multicolumn{16}{|l|}{ Northeast } \\
\hline Burirum (BR) & - & - & 4 & - & - & - & - & - & - & - & - & - & - & - & - \\
\hline Chaiyaphum (CY) & - & - & 3 & - & - & - & - & - & - & - & - & - & - & - & - \\
\hline Khon Kaen (KK) & - & - & 6 & - & - & - & - & - & - & - & - & 1 & - & - & - \\
\hline Maha Sarakham (MK) & - & - & 2 & - & - & - & - & - & - & - & - & - & - & - & - \\
\hline Mukdahan (MD) & - & - & - & - & - & - & - & - & - & - & - & - & - & - & - \\
\hline Nakhon Ratchasima (NR) & - & - & - & - & - & - & - & - & - & - & - & - & - & - & 1 \\
\hline Roi et (RE) & - & - & 2 & - & - & - & - & - & - & - & - & 1 & 2 & - & - \\
\hline Sakhon Nakhon (SN) & - & - & 3 & - & - & - & - & - & - & - & - & - & - & - & - \\
\hline Sisaket (SS) & - & - & 4 & - & 1 & - & - & - & - & - & 1 & - & - & - & - \\
\hline Surin (SU) & - & - & 2 & - & - & - & - & - & - & - & - & 2 & - & - & - \\
\hline Ubon Rachathani (UB) & - & - & 5 & - & 1 & - & - & - & - & - & 2 & 1 & 1 & - & - \\
\hline Udon Thani (UD) & - & - & 1 & - & - & - & - & - & - & - & - & - & - & - & - \\
\hline \multicolumn{16}{|l|}{ Peninsular Thailand } \\
\hline Chumphon (CP) & 3 & - & 22 & - & - & - & - & - & - & - & - & 4 & - & - & - \\
\hline Nakhon Si Thammarat (NT) & 1 & - & 9 & - & - & - & - & - & - & - & - & - & - & - & - \\
\hline Phatthalung (PT) & - & - & - & - & - & - & - & - & - & - & - & 1 & - & - & - \\
\hline Ranong (RN) & - & - & 5 & - & - & - & - & - & - & - & - & - & - & - & - \\
\hline Songkhla (SK) & - & - & - & - & - & - & 2 & - & - & - & 1 & - & - & 1 & - \\
\hline Surat Thani (SR) & - & 1 & 17 & - & - & - & 2 & - & - & 1 & - & 1 & - & 1 & - \\
\hline Total specimens & 12 & 1 & 134 & 1 & 3 & 6 & 4 & 6 & 1 & 1 & 8 & 51 & 7 & 2 & 2 \\
\hline
\end{tabular}

Tapi $=$ Trigona apicalis $;$ Tcan $=T$. canifrons $;$ Tcol $=T$. collina $;$ Tdoi $=T$. doipaensis $;$ Tfim $=T$. fimbriata $;$ Tfus $=T$. fuscobalteata $;$ Titm $=T$. itama ; Tlae $=T$. laeviceps $;$ Tmela $=T$. melanoleuca $;$ Tmel $=T$. melina $;$ Tmin $=T$. minor $;$ Tpag $=T$. pagdeni; Tter $=T$. terminata $;$ Ttho $=T$. thoracica; Lfur = Lisotrigona furva Engel. 


\section{Cloning and sequencing for a candidate T. collina-specific AFLP}

A 316-bp AFLP found in T. collina but not in other screened species was excised, eluted out from the gel and reamplified using the original primers. The product was cloned into pGEM $^{\circledR}$-T Easy vector (Hoelzel and Green, 1992; Sambrook and Russell, 2001). Plasmid DNA was extracted from a recombinant clone and sequenced in both directions. A pair of primers (CUTc1-F: 5'-GGTTCGGATTTGGTTGGCATTG-3' and CUTc1-R: 5'-CGGTGT ACGAAGCGCCAG-3') was designed and tested across the target (134 nests; one individual per nest) and 14 non-target species (Table 1). PCR was carried out in a $25-\mu \mathrm{L}$ reaction volume containing $10 \mathrm{mM}$ Tris- $\mathrm{HCl}, \mathrm{pH} 8.8,50 \mathrm{mM} \mathrm{KCl}, 0.1 \%$ Triton X-100, $2.0 \mathrm{mM} \mathrm{MgCl}, 200$ $\mu \mathrm{M}$ each dNTP, 1 unit DyNAzyme ${ }^{\mathrm{TM}}$ DNA polymerase (Finnzymes), $0.2 \mu \mathrm{M}$ each primer and $0.5 \mu \mathrm{L}$ genomic DNA template.

The amplification reaction was performed by predenaturation at $94^{\circ} \mathrm{C}$ for $3 \mathrm{~min}$, followed by 35 cycles of denaturation at $94^{\circ} \mathrm{C}$ for $30 \mathrm{~s}$, annealing at $56^{\circ} \mathrm{C}$ for $60 \mathrm{~s}$, and extension at $72^{\circ} \mathrm{C}$ for $30 \mathrm{~s}$. The final extension was performed at $72^{\circ} \mathrm{C}$ for $7 \mathrm{~min}$. The amplification product was analyzed by agarose gel electrophoresis (Sambrook and Russell, 2001).

\section{Single-strand conformational polymorphism analysis}

Six microliters of the amplified CUTc1 product of T. collina (134 nests) and T. pagdeni (43 nests) was mixed with four volumes of the loading dye ( $95 \%$ formamide, $0.25 \%$ bromophenol blue, $0.25 \%$ xylene cyanol and $10 \mathrm{mM} \mathrm{NaOH}$ ), denatured at $95^{\circ} \mathrm{C}$ for $5 \mathrm{~min}$, immediately cooled on ice for 2 min and electrophoretically analyzed through $12.5 \%$ nondenaturing polyacrylamide gels $\left(37.5: 1\right.$ crosslink) at $12.5 \mathrm{~V} / \mathrm{cm}$ for $16 \mathrm{~h}$ at $4^{\circ} \mathrm{C}$.

Single-strand conformation polymorphism (SSCP) bands were visualized by silver staining. Allelic polymorphism of the amplified CUTc1 fragment $(\mathrm{N}=10)$ was confirmed by size-fractionated through $6 \%$ denaturing gel electrophoresis.

\section{RESULTS AND DISCUSSION}

\section{Development of a species-specific marker (CUTc1) for authentication of T. collina in Thailand}

Species identification is necessary, particularly when species could be misidentified morphologically (Thummajitsakul et al., 2008, 2010). AFLP is a multiple-locus fingerprinting, enabling the identification of genetic markers at different taxonomic levels, without the need for knowledge of sequences of the genome under investigation (Vos et al., 1995). It has been widely used to study polymorphism among populations and species (Blears et al., 1998; Mueller and Wolfenbarger, 1999) and to identify species-diagnostic markers in various taxa (Liu and Cordes, 2004; Klinbunga et al., 2007).

Using 64 primer combinations against 11 stingless bee species, a 316-bp fragment generated by $P s t \mathrm{I}_{+\mathrm{AGT}} / M e \mathrm{I}_{+\mathrm{CAG}}$ was found in T. collina but not in the other species (Figure 2). Basically, an AFLP approach is composed of several steps (i.e., genomic DNA digestion, adaptor ligation, preselective, and selective amplification of the digested/ligated fragments, PAGE and silver-staining; Muller and Wolfenbarger, 1999), limiting the ability to authenticate 
a large number of specimens within a short period of time. As a result, species-diagnostic sequence-characterized amplified region (SCAR) markers were further developed from candidate species-specific AFLP found in T. collina (hereafter called CUTc1). Nucleotide sequence of CUTc1 (Figure 3) did not match any sequence in the GenBank (E-value $>1 \mathrm{e}-04)$ and was regarded as an anonymous DNA segment.

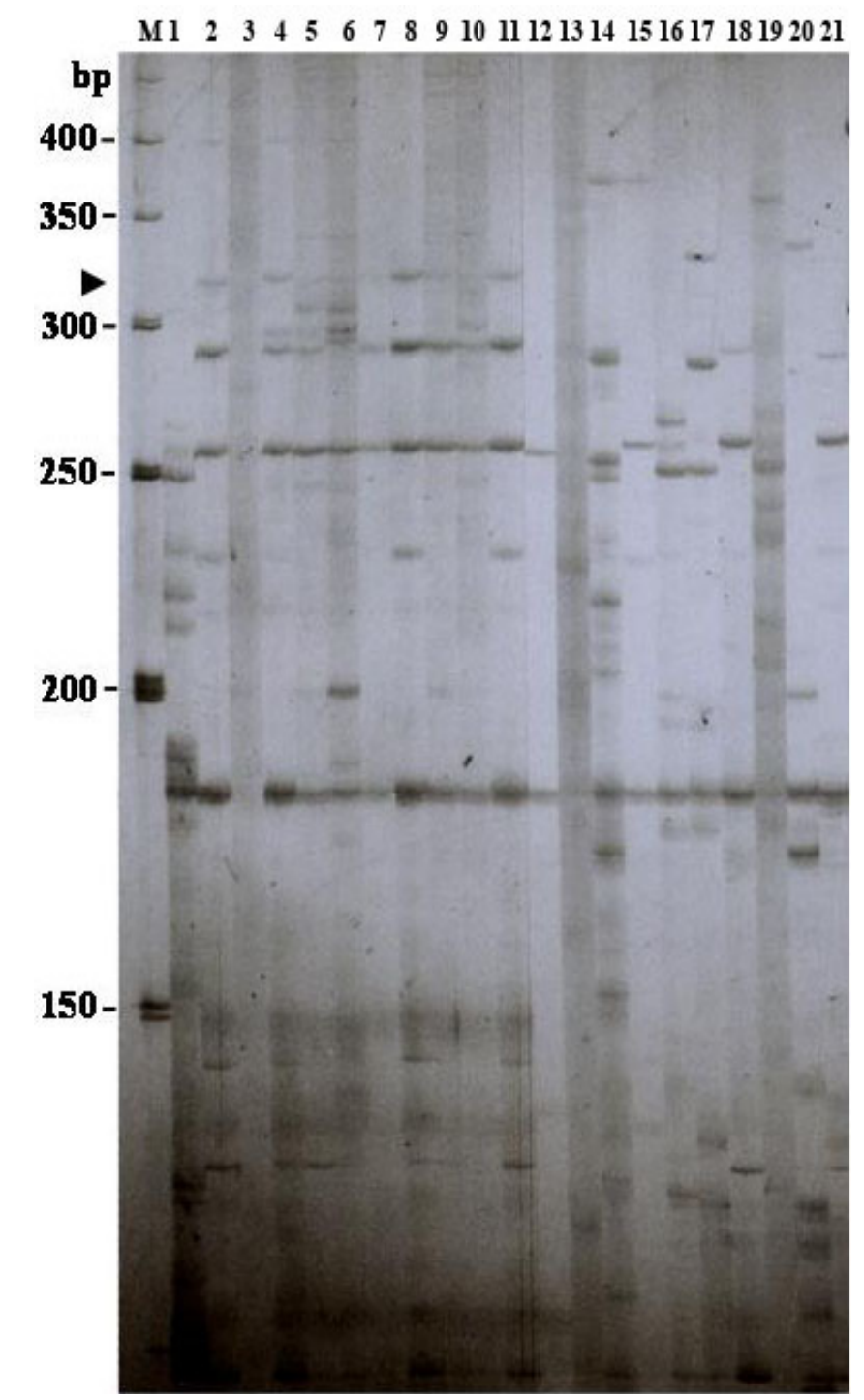

Figure 2. Amplified fragment length polymorphism (AFLP) patterns of various stingless bees; Trigona itama (lanes 1 and 19), T. collina (lanes 2-11), T. pagdeni (lane 12), T. apicalis (lane 13), T. canifrons (lane 14), T. minor (lane 15), T. doipaensis (lane 16), T. thoracica (lane 17), T. fuscobalteata (lane 18), T. fimbriata (lane 20), T. melina

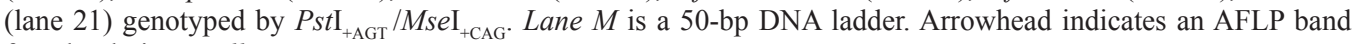
found only in $T$. collina. 


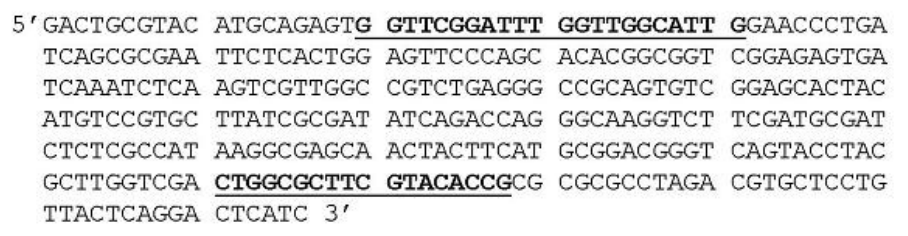

Figure 3. Nucleotide sequence of a Trigona collina-specific amplified fragment length polymorphism ( $316 \mathrm{bp})$. The locations and sequences of a forward primer (CUTc1-F) and those complementary to a reverse primer (CUTc1-R) are illustrated in boldface and underlined.

The developed SCAR marker was tested in larger sample sizes of previously examined species and an additional four stingless bee species (T. laeviceps, T. melanoleuca, T. terminata, and L. furva) (239 nests). The expected amplification product (259 bp) was found in all T. collina individuals (134/134 nests accounting for $100 \%$ of investigated specimens) but not in T. apicalis, T. canifrons, T. doipaensis, T. fimbriata, T. fuscobalteata, T. itama, T. laeviceps, T. melanoleuca, T. melina, T. minor, T. thoracica, and T. terminata and the outgroup L. furva (Table 1). Nevertheless, cross-species amplification was found in T. pagdeni (275 bp, 43/51 nests, 84.3\%; Figure 4). Thus, species-specific PCR of the CUTc1 marker successfully discriminated T. collina from 13 other stingless bee species. Differentiation between T. collina and T. pagdeni can also be carried out based on nest architecture and external morphology (Sakagami, 1978; Sakagami et al., 1985).
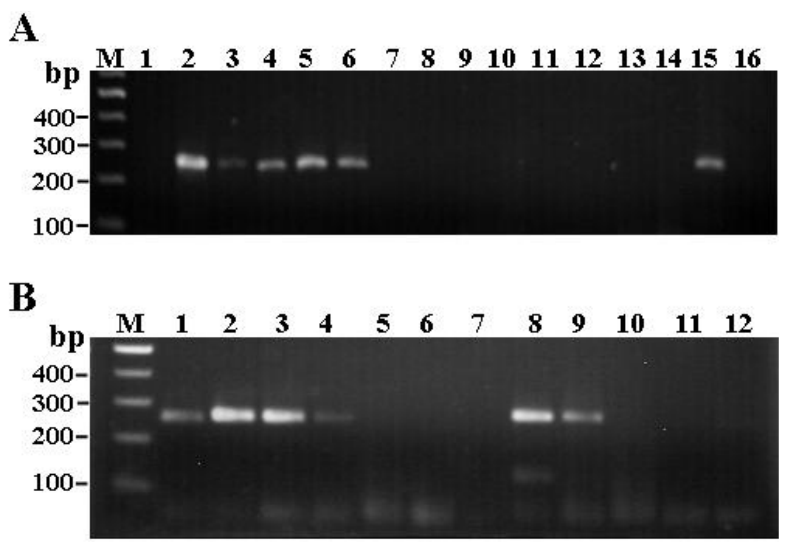

Figure 4. Amplification results of CUTc1 against genomic DNA of Trigona collina (lanes 2-6, A and lanes 1-4, B), T. apicalis (lanes 7-9, A), T. doipaensis (lane 10, A), T. fimbriata (lane 11, A), T. itama (lane 12, A), T. minor (lane 13, A), T. fuscobalteata (lane 14, A), T. pagdeni (lanes 15, A and lanes 8,9, B), T. melanoleuca (lane 16, A), T. laeviceps (lane 5, B), L. furva (lane 6, B), T. melina (lane 7, B), T. terminata (lane 10, B), T. thoracica (lane 11, B), and T. canifrons (lane 12, B). Lanes $M$ (A and B) and lane 1 (A) are a 100-bp DNA ladder and the negative control (without genomic DNA template), respectively.

SSCP analysis, which is favored for identifying species origins of various taxa, due to its convenience and cost-effectiveness (Orita et al., 1989; Weder et al., 2001; Klinbunga et al., 2007), was then applied to determine whether nucleotide sequences of CUTc1 in T. pagdeni 
and T. collina were different. Non-overlapping SSCP patterns between T. collina and T. pagdeni were observed (Figure 5A). Nucleotide sequences of representative individuals of these species were different, owing to a 15-bp indel (CGGCCGCCAAGCGGC) and several single nucleotide polymorphisms (SNPs). In addition, within species SNPs were also observed in $T$. pagdeni (Figure 5B). Therefore, a species-diagnostic marker for T. collina was successfully developed; this is convenient for molecular geneticists who are not familiar with species differentiation based on nest architecture and external morphology of stingless bees.

$\mathbf{A}$

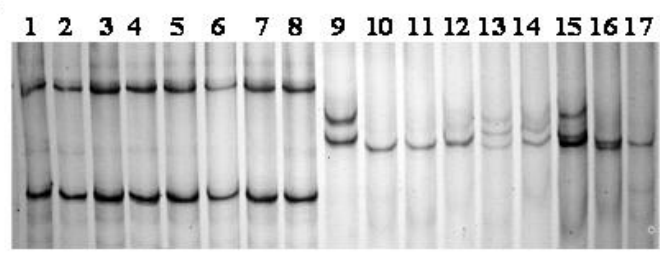

B

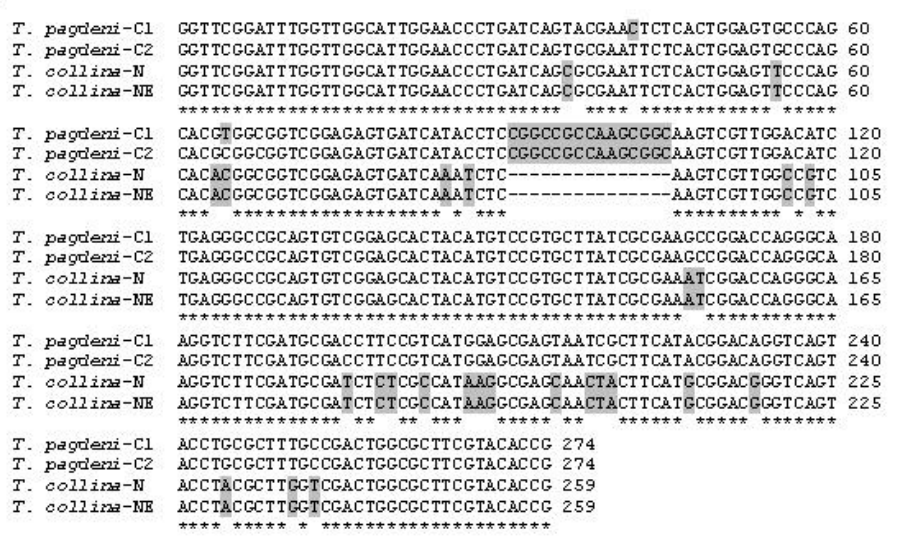

Figure 5. Single-strand conformation polymorphism patterns of the amplified CUTc1 of Trigona collina (lanes 1-8, A) and T. pagdeni (lanes 9-17, A) and nucleotide sequences of CUTc1 (B) in representative individuals of T. collina originating from the north $(\mathrm{N})$ and northeast $(\mathrm{NE})$ and T. pagdeni originating from the central region $(\mathrm{C})$, respectively.

In Brazil, Melipona quadrifasciata quadrifasciata, which possesses 3-5 continuous yellow stripes, and M. quadrifasciata anthidiodes, which possesses 2-5 interrupted stripes on the terga of the 3rd and 6th segments in workers and males, have been found. Inter-subspecific hybrids exhibiting intermediate stripe patterns were found in some areas of Brazil. A 750-bp RAPD marker from OPE07 was present in the former, except stingless bees from northern Minas Gerais but was absent in the latter subspecies (Waldschmidt et al., 2000). Restriction analysis of cytochrome b with VspI could also differentiate these subspecies (Souza et al., 2008).

Recently, a species-diagnostic AFLP-derived marker for identification of T. pagdeni was successfully developed. The expected 163-bp fragment (CUTp1) was successfully amplified in all examined individuals of T. pagdeni (129/129 nests). Nevertheless, cross-species amplification was also observed in $T$. fimbriata (1/3 nests), T. collina (11/112 nests), T. laeviceps (1/12 nests), and T. fuscobalteata (15/15 nests) but not in T. apicalis, T. canifrons, T. itama, T. melina, T. minor, T. terminata, T. doipaensis, T. melanoleuca, T. thoracica, and L. furva. 
SSCP analysis of CUTp1 further differentiated T. fuscobalteata and T. collina from T. pagdeni. Although, T. laeviceps, T. fimbriata and T. pagdeni shared an identical SSCP genotype, they are not taxonomically problematic species (Thummajitsakul et al., 2010). Accordingly, both CUTc1 (this study) and CUTp1 (Thummajitsakul et al., 2010) should be concurrently used to eliminate possible misidentification problems between T. collina and T. pagdeni when new geographic populations of these species are examined.

\section{Application of CUTc1 for determining genetic population structure of $T$. collina in Thailand}

Basic knowledge of genetic population structure is required for effective management of native bee species (Thummajitsakul et al., 2008). Population genetic studies of the Asian honey bee (Apis cerana) in Thailand using mitochondrial DNA and microsatellite polymorphism revealed the biogeographical transition area between Mainland and Sundaland populations located at the Kra ecotone (at Tup Sa Kae, Prachup Kiri Khan, $11^{\circ} 31^{\prime} \mathrm{N}, 99^{\circ} 35^{\prime} \mathrm{E}$,

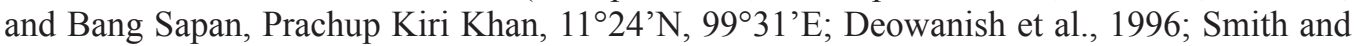
Hagen, 1996, 1999; Sihanuntavong et al., 1999; Warrit et al., 2006). A pattern of geographic differentiation of the giant honey bee (Apis dorsata) in Thailand between north-to-central and peninsular Thailand populations was also noticed found, based on microsatellite analysis (Insuan et al., 2007).

Genotypic distribution patterns of CUTc1 were different in stingless bee from the north-to-central region (259/259-bp alleles corresponding to the AA genotype found in $76 / 81$ nests) sample and most individuals of $T$. collina from peninsular Thailand (253/253bp alleles corresponding to the BB genotype found in $42 / 53$ nests) when examined by SSCP analysis (Figure 6A). In addition, heterozygotes exhibiting 253/259-bp alleles (AB genotype) were observed in stingless bees from Prachuap Khiri Khan located slightly above the Kra ecotone (5/28 nests) and those from peninsular Thailand (Chumphon, Ranong, Surat Thani, and Nakon Si Thammarat, 11/53 nests). Genotypic differences between these specimens were consistent when the amplified products of CUTc1 from representative individuals carrying $\mathrm{AA}, \mathrm{AB}$ and $\mathrm{BB}$ genotypes were re-examined by denaturing gel electrophoresis (Figure 6B). Nucleotide sequences of stingless bees carrying different homozygotic genotypes indicated allelic polymorphism owing to a 6-bp indel (GACCAG) present in AA but absent in BB genotypes.

Genotype distribution patterns of CUTc1 strongly suggested biogeographic differentiation between T. collina originating from north and south of the Kra ecotone, as previously reported for T. pagdeni, based on three enzyme-AFLP analysis (Thummajitsakul et al., 2008).

The information in this and previous studies confirms that the Kra ecotone is the major physical barrier limiting gene flow of honey bees (A. cerana and $A$. dorsata) and stingless bees (T. collina and T. pagdeni) in Thailand.

We developed a species-diagnostic marker for T. collina. The CUTc1 SCAR marker is convenient and cost effective for differentiation of $T$. collina from other stingless bees in Thailand; this will help prevent misidentification species for molecular systematics of stingless bees and for population genetics studies of T. collina. Additional species-diagnostic markers for other stingless bee species could also be developed by the same approach to resolve taxonomic difficulties of indigenous bee species in Thailand. 
A

B

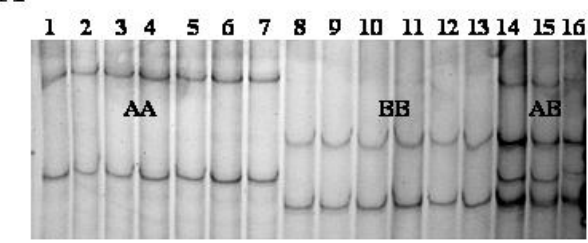

$\begin{array}{llllllllll}1 & 2 & 3 & 4 & 5 & 6 & 7 & 8 & 9 & 10\end{array}$

C

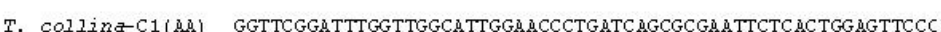

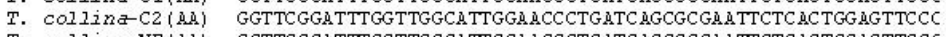
T. Collina-NE $(\dot{\mu} \hat{\mu})$ GGTTCGGATTTGGTTGGCATTGGMACCCTGATCAGCGCGMATTCTC ACTGGAGTTCCC

T. COI ina 5 (BD) GCTTCGGATTTCGTTGGCATTGGA

G GTTCGCATTGGTTGGCATTGGACCCTGATCAGCGCGMATTCTCACTGGAGTTCCC

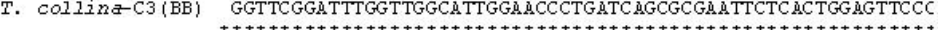

T. Collina-C1(h) CACACGGCGGTCGGMGAGTGATCAMATCTCMAGTCGTTGGCCGTCTGMGGGCCGCAGT

T. collina-C2 (AM) CACACGGCGGTCGGAGAGTGATCAAMTCTCHAGTCGTTGGCCGTCTGAGGGCCGCAGT

T. CollinaNE (Ai) CACACGGCGGTCGGAGAGTGATCA ATCTCHAGTCGTTGGCCGTCTGMGGGCCGCHGI

T. collina $\mathrm{S}$ (BB) CACACGGCGGTCGGAGAGTGATCAAMTCTCAMGTCGTTGGCCGTCTGAGGGCCGCAGI

T. Collina-C3(BB) CACACGGCGGTCGGAGAGTGATCAMATCTCAMGTCGTTGGCCGTCTGMGGGCCGCAGT

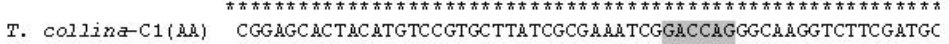

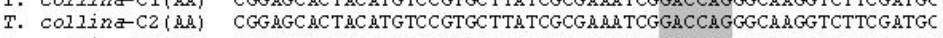

T. Collina-NE (מß) CGGAGCACTACATGTCCGTGCTTATCGCGMATCGGACCAGGGCAGGTCTTCGATGC

T. Collinas (BB) CGGAGCACTACATGTCCGTGCTTATCGCGAMATCG------GGCAMGGTCTTCGATGC

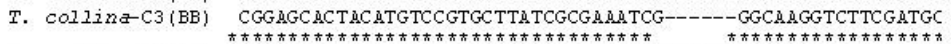

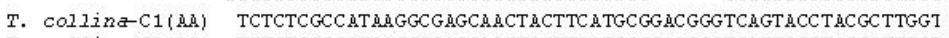

T. Collina-C2 (씨) TCTCTCGCCATAMGGCGAGCAACTACTTCA TGCGGACGGGTCAGTACCTACGCTTGGT

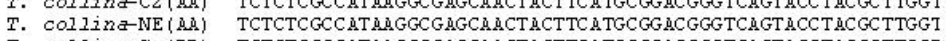

T. Collina 5 (BB) TCTCTCGCCATAMGGCGAGCAACTACTTCATGCGGACGGGTCAGTACCTACGCTTGGI

T. Collina-C3(BB) TCTCTCGCCATAMGGCGAGCAMCTACTTCATGCGGACGGGTCAGTACCTACGCTTGGT

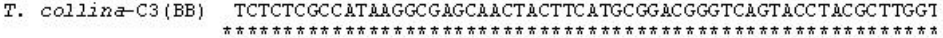

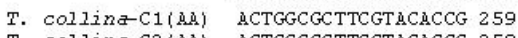

T. collina-C2 (A.A) ACTGGCGCTTCGTACACCG 259

T. Collina-NE ( $\mathbf{A} \hat{\mathrm{a}})$ ACTGGCGCTTCGTACACCG 259

T. Collina-S (BB) ACTGGCGCTTCGTACACCG 253 T. collina-C3 (BB) ACTGGCGCTTCGTACACCG 253

Figure 6. The amplified CUTc1 against genomic DNA of Trigona collina fractionated on $12.5 \%$ non-denaturing polyacrylamide (SSCP) gel electrophoresis (A) and 6\% denaturing (B). Three genotypes; AA (lanes 1-7, A and lanes 1-5, B), BB (lanes 8-13, A and lanes 6-8, B) and AB (lanes 14-16, A and lanes 9,10, B) were observed. Nucleotide sequence of CUTc1 in T. collina possessing the AA genotype (259/259-bp alleles; T. collina - C1, T. collina - C2 and T. collina - NE) and the BB genotype (253/253-bp alleles; T. collina - S and T. collina - C3) are illustrated in $C$.

\section{ACKNOWLEDGMENTS}

We thank the Bee Research Unit, Faculty of Science, Chulalongkorn University and National Center for Genetic Engineering and Biotechnology (BIOTEC), Thailand, for providing facilities. A student grant (M. Theeraapisakkun) was supported by the Royal Golden Jubilee Ph.D. program (Grant \#PHD//0004/2548), and the Thailand Research Funds (TRF) provided funding.

\section{REFERENCES}

Amano K, Nemoto T and Heaed TA (2000). What are stingless bees, and why and how to use them as crop pollinators? A review. Jpn. Agric. Res. Q. 34: 183-190.

Blears MJ, De Grandis SA, Lee H and Trevors JT (1998). Amplified fragment length polymorphism (AFLP): a review of 
the procedure and its applications. J. Ind. Microbiol. Biotechnol. 21: 99-114.

Deowanish S, Nakamura J, Matsuka M and Kimura K (1996). MtDNA variation among subspecies of Apis cerana using restriction fragment length polymorphism. Apidologie 27: 407-413.

Dollin AE, Dollin LJ and Sakagami SF (1997). Australian stingless bees of the genus Trigona (Hymenoptera: Apidae). Invert. Taxon. 11: 861-896.

Franck P, Cameron E, Good G, Rasplus JY, et al. (2004). Nest architecture and genetic differentiation in a species complex of Australian stingless bees. Mol. Ecol. 13: 2317-2331.

Heard TA (1999). The role of stingless bees in crop pollination. Annu. Rev. Entomol. 44: 183-206.

Hoelzel AR and Green A (1992). Analysis of Population-Level Variation by Sequencing PCR-Amplified DNA. In: Molecular Genetic Analyses of Populations: a Practical Approach (Hoelzel AR, ed.). IRL Press, Oxford, 159-187.

Insuan S, Deowanish S, Klinbunga S, Sittipraneed S, et al. (2007). Genetic differentiation of the giant honey bee (Apis dorsata) in Thailand analyzed by mitochondrial genes and microsatellites. Biochem. Genet. 45: 345-361.

Klakasikorn A, Wongsiri S, Deowanish S and Duangphakdee O (2005). New record of stingless bees (Meliponini: Trigona) in Thailand. Nat. Hist. J. Chulalongkorn Univ. 5: 1-7.

Klinbunga S, Khetpu K, Khamnamtong B and Menasveta P (2007). Development of a species-diagnostic SCAR marker of the blue swimming crab (Portunus pelagicus). Biochem. Genet. 45: 755-760.

Liu $\mathrm{Z}$ and Cordes JF (2004). DNA markers technologies and their applications in aquaculture genetics. Aquaculture 238: $1-37$.

Michener CD (1961). Observations on the nests and behavior of Trigona in Australia and New Guinea (Hymenoptera, Apidae). Am. Mus. Novit. 2026: 1-46.

Michener CD (1974). The Social Behavior of the Bees, a Comparative Study. Belknap Press of Harvard University Press, Cambridge.

Michener CD (2007). The Bees of the World. Johns Hopkins Press, Baltimore.

Michener CD and Sakagami SF (1990). Classificarion of the Apidae (Hymenoptera). Appendix: Trigona genalis Friese, a hitherto unplaced New Guinea species. Univ. Kansas Sci. Bull. 54: 75-164.

Michener CD and Boongird S (2004). A new species of Trigona from peninsular Thailand (Hymenoptera: Apidae: Meliponini). J. Kansas Entomol. Soc. 77: 143-146.

Mueller UG and Wolfenbarger LL (1999). AFLP genotyping and fingerprinting. Trends Ecol. Evol. 14: 389-394.

Orita M, Iwahana H, Kanazawa H, Hayashi K, et al. (1989). Detection of polymorphisms of human DNA by gel electrophoresis as single-strand conformation polymorphisms. Proc. Natl. Acad. Sci. U. S. A. 86: 2766-2770.

Sakagami SF (1978). Tetragonula stingless bees of the Continental Asia and Sri Lanka (Hymenoptera, Apidae). J. Fac. Sci. Hokkaido Univ. Ser. VI. Zool. 21: 165-247.

Sakagami SF and Khoo SG (1987). Taxonomic status of the Malaysian stingless bee Trigona reepeni, with discovery of Trigona pagdeni from northern Malaya. Kontyû 55: 207-214.

Sakagami SF, Inoue T, Yamane S and Salmah S (1983). Nest architecture and colony composition of the Sumatran stingless bee Trigona (Tetragonula) laeviceps. Kontyû 51: 100-111.

Sakagami SF, Inoue T and Salmah S (1985). Key to the Stingless Bee Species Found or Expected from Sumatra. In: Evolutionary Ecology of Insects in Humid Tropics, Especially in Central Sumatra (Ohgushi RI, ed.). Kanazawa University, Japan, Sumatra Nature Study, 37-43.

Sambrook J and Russell DW (2001). Molecular Cloning: A Laboratory Manual. 3rd edn. Cold Spring Harbor Laboratory Press, New York.

Schwarz HF (1939). The Indo-Malayan species of Trigona. Bull. Am. Mus. Nat. Hist. 76: 83-141.

Sihanuntavong D, Sittipraneed S and Klinbunga S (1999). Mitochondrial DNA diversity and population structure of the honey bee, Apis cerana, in Thailand. J. Apic. Res. 38: 211-219.

Slaa EJ, Sanchez LA, Sandi M and Salazar W (2000). A scientific note on the use of stingless bees for commercial pollination in enclosures. Apidologie 31: 141-142.

Slaa EJ, Chaves LAS, Malagodi-Braga KS and Hofstede FE (2006). Stingless bees in applied pollination: practice and perspectives. Apidologie 37: 293-315.

Smith DR and Hagen RH (1996). The biogeography of Apis cerana as revealed by mitochondrial DNA sequence data. $J$. Kansas Entomol. Soc. 69: 294-310.

Smith DR and Hagen RH (1999). Phylogeny and Biogeography of Apis cerana Subspecies: Testing Alternative Hypotheses. In: Apiculture for the 21st Century (Hoopingarner R and Connor L, eds.). Wicwas Press, Cheshire, 60-68.

Souza RO, Moretto G, Arias MC and Del Lama MA (2008). Differentiation of Melipona quadrifasciata L. (Hymenoptera, Apidae, Meliponini) subspecies using cytochrome b PCR-RFLP patterns. Genet. Mol. Biol. 31: 445-450.

Starr CK and Sakagami SF (1987). An extraordinary concentration of stingless bee colonies in the Philippines, with notes 
on nest structure (Hymenoptera: Apidae: Trigona spp.). Insect. Soc. 34: 96-107.

Thummajitsakul S, Klinbunga S, Smith D and Sittipraneed S (2008). Genetic diversity and population structure of Trigona pagdeni Schwarz in Thailand. Apidologie 39: 446-455.

Thummajitsakul S, Klinbunga S and Sittipraneed S (2010). Development of a species-diagnostic marker for identification of the stingless bee Trigona pagdeni in Thailand. Biochem. Genet. 48: 181-192.

Vos P, Hogers R, Bleeker M, Reijans M, et al. (1995). AFLP: a new technique for DNA fingerprinting. Nucleic Acids Res. 23: 4407-4414.

Waldschmidt AM, de Barros EG and Campos LAO (2000). A molecular marker distinguishes the subspecies Melipona quadrifasciata quadrifasciata and Melipona quadrifasciata anthidioides (Hymenoptera: Apidae, Meliponinae). Genet. Mol. Biol. 23: 609-611.

Warrit N, Smith DR and Lekprayoon C (2006). Genetic subpopulations of Varroa mites and their Apis cerana hosts in Thailand. Apidologie 37: 19-30.

Weder JKP, Rehbein H and Kaiser KP (2001). On the specificity of tuna-directed primers in PCR-SSCP analysis of fish and meat. Eur. Food Res. Technol. 213: 139-144. 